\title{
Carga formal
}

A noção de carga formal é especialmente importante em Química Orgânica ao escrever estruturas contribuintes de híbridos de ressonância. Ao iniciar um dos cursos de Química Orgânica e ao procurar que os alunos recordassem esta noção para a aplicar na escrita das estruturas contribuintes, notei que os alunos não sabiam o que era carga formal de um átomo, embora alguns dissessem que carga formal era o

"(Número de electrões de valência no átomo livre) - (Número total de electrões não ligantes) - 1/2 (Número total de electrões ligantes)"

Os alunos, ou não sabiam, ou tinham uma ideia muito nebulosa do assunto.

Achei estranha esta forma complicada de definir carga formal, sem explicar afinal o que ela é, e procurei nos livros correntes de Química Geral [1] o modo como a noção era introduzida, encontrando aí a origem deste modo incrível de apresentar o assunto. Alguns livros até dão um ar matemático ao assunto e escrevem

$$
F C=V-(L+1 / 2 S)
$$

referindo o significado das variáveis $F C$, $V$, L e $S$... Um manual de Química Orgânica [2] escreve no índice "Fórmula para calcular a carga formal" e no texto decalca este modo infeliz de definir carga formal. Um outro livro de Química Geral [3] introduz o conceito claramente, mas na página seguinte resvala para o cálculo da carga formal "a partir da equação"...
Para que os alunos compreendam o que se entende por carga formal é necessário que se diga simplesmente o que ela é, isto é, a carga que um átomo adquiriria se as ligações que faz com outros átomos fossem partidas homoliticamente. Como se exemplifica na figura 1.

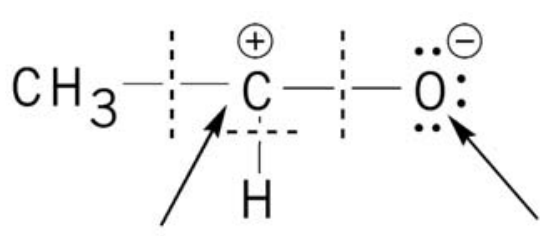

$$
\begin{array}{ll}
\begin{array}{l}
\text { Rodeado por } 3 \text { electrões } \\
\text { (um a menos que o C livre) }
\end{array} & \begin{array}{l}
\text { Rodeado por } 7 \text { electrões } \\
\text { (um a mais que o O livre) }
\end{array} \\
\text { Carga formal do carbono }=4-3=+1 & \\
\text { Carga formal do oxigénio }=6-7=-1 & \\
\text { (Por carbono livre entende-se um átomo de carbono não ligado) }
\end{array}
$$

\section{Figura 1 Carga formal e cisão homolítica}

Note-se que esta noção é semelhante à de número de oxidação, com a diferença de que aqui os electrões das ligações covalentes são atribuídos aos átomos mais electronegativos (cisão heterolítica) ou repartidos no caso de átomos do mesmo elemento. Como se exemplifica na figura 2.

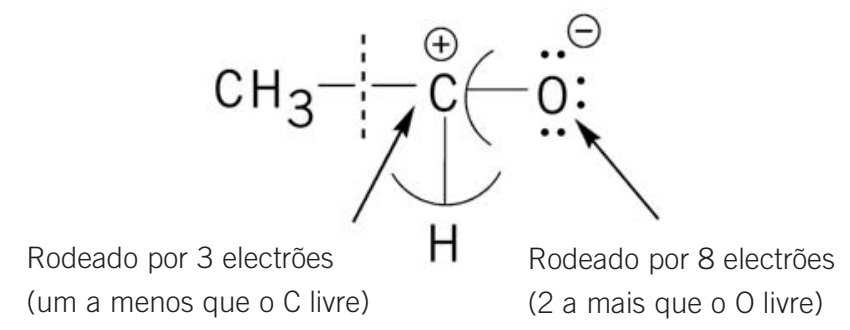

Número de oxidação do carbono $=4-3=+1$

Número de oxidação do oxigénio $=6-8=-2$

Figura 2 Número de oxidação e cisão heterolítica

\footnotetext{
* Departamento de Química da Faculdade de Ciências do Porto (ccorrea@fc.up.pt)
} 
Em resumo: os dois conceitos são simplesmente paralelos (figura 3) Narga formal é ...

Figura 3 Paralelismo carga formal/número de oxidação
Para quê complicar o que é tão simples?
Referências:

1 R.Chang, "Chemistry", 4. ${ }^{a}$ edição, pag. 369 McGraw-Hill, (1991); P. Atkins e L. Jones, "Chemistry, Molecules, Matter, and Change", 3. a edição, Pag. 282 (1997).

2 K. P. C. Vollhardt e N. E. Schore, "Organic Chemistry, Structure and Function", W. H. Freeman \& Company, pag.16 (1998).

3 D. Reger, S. Goode e E. Mercer, "QUÍMICA, Princípios e Aplicações”, Tradução portuguesa, pag. 347 e 348, Fundação Calouste Gulbenkian (1997).

\section{Catalisadores de Baixo Custo para a Indústria Automóvel}

Os automóveis que circulam nas nossas estradas possuem catalisadores baseados em metais nobres para o tratamento dos gases de exaustão libertados na queima dos combustíveis nos seus motores. Esses catalisadores são também conhecidos como catalisadores de "três vias", por promoverem três reacções em simultâneo: oxidação de monóxido de carbono e de hidrocarbonetos não consumidos e redução de óxidos de azoto $\left(\mathrm{NO}_{\mathrm{x}}\right)$.

Nos motores, o combustível é queimado em proporções próximas da razão ar/ /combustível estequiométrica, não se conseguindo desta forma maximizar a eficiência do combustível. Esta pode ser aumentada se a queima do combustível se realizar em excesso de oxigénio. De forma a reduzir o consumo de combustível nos automóveis, tem-se procurado desenvolver novos catalisadores, uma vez que os catalisadores convencionais de "três vias" não permitem a redução de $\mathrm{NO}_{x}$ em excesso de oxigénio.

Os catalisadores de armazenamento e redução de $\mathrm{NO}_{x}$ (NSR), que alternada- mente capturam os óxidos num componente de bário em determinadas condições e os reduzem sob outras condições, são uma solução promissora para o problema da combustão em excesso de oxigénio. No entanto, até recentemente, estes catalisadores alternativos, que se encontram já em testes de estrada no Japão e outros países, são baseados em metais nobres de elevado custo, como a platina e o ródio.

Recentemente, um grupo de Engenheiros Químicos da Universidade de Delaware, desenvolveu um catalisador NSR que usa cobalto como metal de oxidação e não contém metais nobres. 0 catalisador desenvolvido é tão eficiente no tratamento de NOx, como os catalisadores NSR baseados em platina (Catal. Commun 6 (2005) 167.

Usando um reactor de elevado desempenho para testar 16 catalisadores em paralelo, a equipa de Delaware estudou o efeito de pequenas concentrações de manganês, ferro e cobalto na performance dos catalisadores NSR. Descobriram que um catalisador suportado em alumina contendo $5 \%$ de cobalto e $15 \%$ de bário é tão eficiente como uma for- mulação de um catalisador NSR convencional contendo $1 \%$ de platina. Os investigadores observaram ainda que, adicionando $1 \%$ de platina ao catalisador de cobalto-bário, se produz um material com uma capacidade de armazenamento de $\mathrm{NO}_{\mathrm{x}}$ duas vezes superior à dos tradicionais catalisadores NSR baseados em platina.

Baseando-se em estudos de difracção de raios $X$, a equipa propõe que 0 aumento da capacidade de armazenamento do $\mathrm{NO}_{x}$ resultante da presença do cobalto é devido em parte a $\mathrm{CO}_{3} \mathrm{O}_{4}$, que participa na oxidação de $\mathrm{NO}$ a NO 2 (um passo essencial no mecanismo de armazenamento do $\mathrm{NO}_{x}$ ). A equipa sugere ainda que a grande proximidade do $\mathrm{CO}_{3} \mathrm{O}_{4}$ aos centros de armazenamento de bário, aumenta o contacto interfacial entre os componentes de oxidação e de armazenamento, que por sua vez, provoca um aumento na eficiência de armazenamento de $\mathrm{NO}_{x}$. (adaptado de Chemical \& Engineering News 83 (5) (2005) 9)

Helder Gomes 